\title{
Oak Ridge National Laboratory Initial Radiation of Nuclear Power Plant Components - Final CRADA Report
}

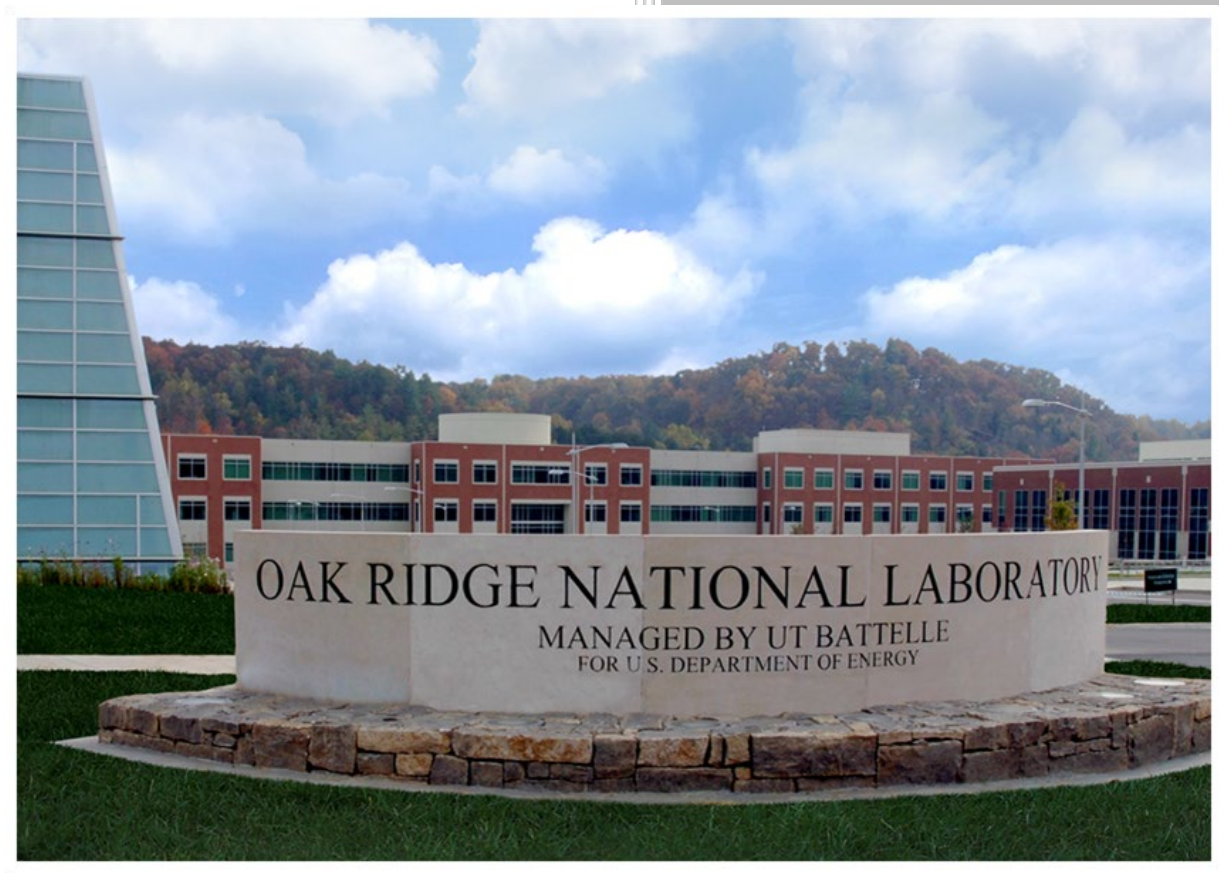
CRADA number NFE-17-06892

Approved for public release. Distribution is unlimited.

Robert Duckworth

Edwin Riggsbee

Alex Hashemian

Shawn Tyler

October 2019 


\title{
DOCUMENT AVAILABILITY
}

Reports produced after January 1, 1996, are generally available free via US Department of Energy (DOE) SciTech Connect.

Website www.osti.gov

Reports produced before January 1, 1996, may be purchased by members of the public from the following source:

\author{
National Technical Information Service \\ 5285 Port Royal Road \\ Springfield, VA 22161 \\ Telephone 703-605-6000 (1-800-553-6847) \\ TDD 703-487-4639 \\ Fax 703-605-6900 \\ E-mail info@ntis.gov \\ Website http://classic.ntis.gov/
}

Reports are available to DOE employees, DOE contractors, Energy Technology Data Exchange representatives, and International Nuclear Information System representatives from the following source:

Office of Scientific and Technical Information

PO Box 62

Oak Ridge, TN 37831

Telephone 865-576-8401

Fax 865-576-5728

E-mail reports@osti.gov

Website http://www.osti.gov/contact.html

This report was prepared as an account of work sponsored by an agency of the United States Government. Neither the United States Government nor any agency thereof, nor any of their employees, makes any warranty, express or implied, or assumes any legal liability or responsibility for the accuracy, completeness, or usefulness of any information, apparatus, product, or process disclosed, or represents that its use would not infringe privately owned rights. Reference herein to any specific commercial product, process, or service by trade name, trademark, manufacturer, or otherwise, does not necessarily constitute or imply its endorsement, recommendation, or favoring by the United States Government or any agency thereof. The views and opinions of authors expressed herein do not necessarily state or reflect those of the United States Government or any agency thereof. 
ORNL/ TM-2019/1398

CRADA/NFE-17-06892

\title{
US DEPARTMENT OF ENERGY
}

Office of Nuclear Energy

Gateway for Accelerated Innovation in Nuclear (GAIN) Program

\section{INITIAL RADIATION OF NUCLEAR POWER PLANT COMPONENTS} FINAL CRADA REPORT

\author{
Robert Duckworth \\ Edwin Riggsbee \\ Alex Hashemian \\ Shawn Tyler
}

October 2019

Prepared by

OAK RIDGE NATIONAL LABORATORY

Oak Ridge, TN 37831-6283

managed by

UT-BATTELLE, LLC

for the

US DEPARTMENT OF ENERGY

under contract DE-AC05-00OR22725 



\section{CONTENTS}

CONTENTS

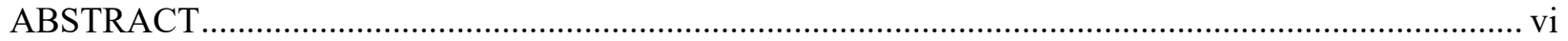

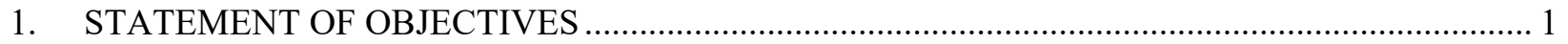

2. BENEFITS TO THE FUNDING DOE OFFICE'S MISSION …............................................ 1

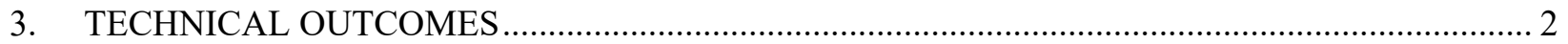

3.1 HFIR INSTRUMENTED GAMMA SYSTEM INTEGRATION ….................................... 2

3.2 EXPERIMENTAL ASSEMBLY DESIGN AND FABRICATIONS .................................... 4

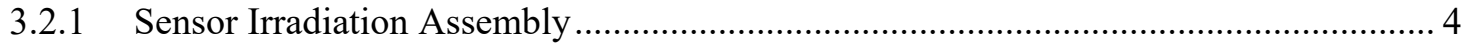

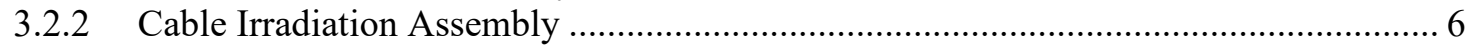

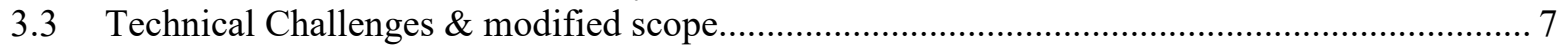

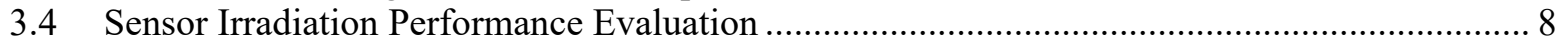

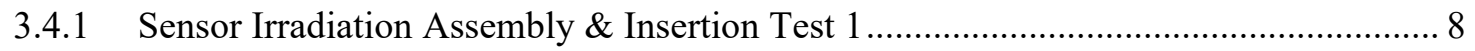

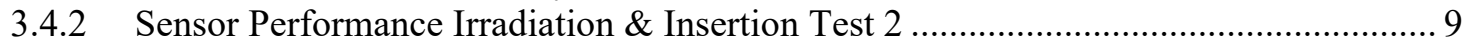

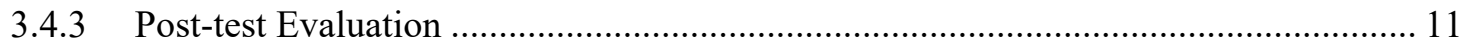

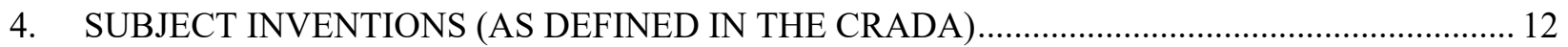

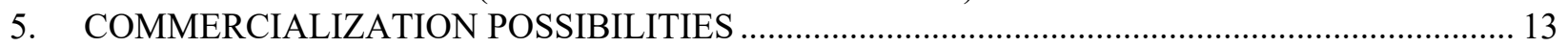

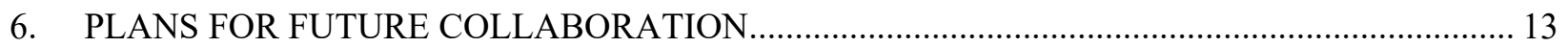

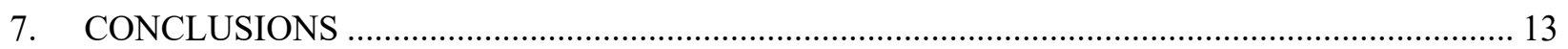

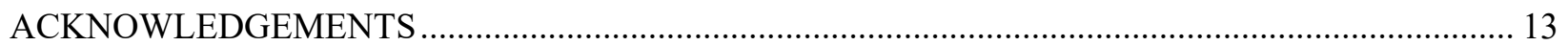




\begin{abstract}
As advanced reactor concepts are developed, instrumentation and control (I\&C) cables and sensors will play a significant role in assuring their operation is well understood, and safety-related process information can be collected reliably over the course of their design life. As a first step to develop acceptance criteria and define the limits of currently available nuclear I\&C cable and sensor technology, a collaboration between Oak Ridge National Laboratory and Analysis and Measurement Services (AMS) Corporation was initiated under the Gateway for Accelerated Innovation in Nuclear (GAIN) Program. This collaborative effort focused on providing technical information related to the combined thermal and radiation aging of nuclear power plant (NPP) cables, companion NPP cable insulation samples, and two prototype temperature and two pressure sensors. This work was carried out using the instrumented gamma irradiation system that is part of the High Flux Isotope Reactor Gamma Irradiation Facility (HFIR GIF). This system provided the opportunity for the condition of the prototype sensors to be tracked during the irradiation in order to determine their functional limits with greater granularity when compared to a simple irradiation insertion at the HFIRGIF. Experimental assemblies for sensor irradiation were successfully completed, and sensor irradiation to accumulated dose of $3000 \mathrm{kGy}$ at a rate of approximately $6 \mathrm{kGy} / \mathrm{hr}$ was carried out.
\end{abstract}

Two prototype temperature assemblies were continuously monitored during exposure to $3000 \mathrm{kGy}$ and found to have no observable degradation from the irradiation. Two pressure sensors were first irradiated to $1000 \mathrm{kGy}$. At which point, one of the sensors was found to operate normally; however, a second sensor failed the operability test. The operable pressure sensor output was then continuously monitored from 1000 kGy to $3000 \mathrm{kGy}$. The sensor output exhibited steady trendable drift versus the accumulated radiation dose. At the conclusion of the irradiation, the four test sensors were released for laboratory calibration checks. The calibration check of the temperature sensors found no significant change after irradiation compared to baseline measurements before irradiation; however, both pressure sensors failed the post-test calibration checks and both sensors were not functioning properly. These results will help inform sensor manufacturers and I\&C design engineers of potential limitations of these types of sensors for use in high radiation environments associated with the compact configuration of new Small Modular Reactors (SMRs) such as NuScale's reactor power module.

Irradiations on NPP cables and companion samples were not completed due to programmatic delays, however a path forward that was based on lessons learned from this project was defined to accommodate future, comparable instrumented gamma irradiations at the HFIR GIF. 


\section{STATEMENT OF OBJECTIVES}

The technical objectives for this CRADA involved the combined thermal/radiation aging of nuclear power plant (NPP) cables, companion NPP cable insulation samples, and prototype pressure and temperature sensors to demonstrate feasibility in current and future reactor environments. This irradiation was carried out in the instrumented gamma irradiation system that is part of the High Flux Isotope Reactor Gamma Irradiation Facility (HFIR GIF). This system provided the opportunity for the condition of the prototype sensors to be tracked during the irradiation in order to determine their functional limits with greater granularity when compared to a simple irradiation insertion at a HFIR GIF pool temperature without external controls. More specifically, the outputs of the prototype temperature and pressure sensors were monitored by Analysis and Measurement Services (AMS) Corporation staff in the experimental area at HFIR.

Table 1 summarizes the targeted irradiation campaigns at the HFIR GIF. Periodic removal of the gamma irradiation canister was planned during each irradiation either to remove companion NPP samples during cable irradiations or inspect sensor condition during their irradiation. After inspection and release from the HFIR GIF irradiation area, post-irradiation examination of cables, samples, and sensors by AMS was planned to assess the final condition of the materials and their feasibility relative to current environmental conditions found in current and future reactor environments. It was expected that all five irradiation campaigns could be completed in one year given the current HFIR activities in the HFIR GIF and the other HFIR facilities.

Table 1. Summary of planned irradiation conditions for combined thermal/radiation aging of NPP cables, companion NPP cable samples, and prototype sensors at HFIR GIF.

\begin{tabular}{|c|c|c|c|c|c||}
\hline \multirow{2}{*}{ Test Conditions } & \multicolumn{3}{|c|}{ Cable Tests } & \multicolumn{2}{c||}{ Sensor Tests } \\
\cline { 2 - 6 } & Test 1 & Test 2 & Test 3 & Test 4 & Test 5 \\
\hline Dose Rate & $500 \mathrm{~Gy} / \mathrm{hr}$ & $500 \mathrm{~Gy} / \mathrm{hr}$ & $10 \mathrm{~Gy} / \mathrm{hr}$ & $10 \mathrm{kGy} / \mathrm{hr}$ & $10 \mathrm{kGy} / \mathrm{hr}$ \\
\hline Exposure Time & $15 \mathrm{days}$ & 42 days & 2 days & 6 days & 6 days \\
\hline Total Dose & $180 \mathrm{kGy}$ & $500 \mathrm{kGy}$ & $500 \mathrm{kGy}$ & $1500 \mathrm{kGy}$ & $1500 \mathrm{kGy}$ \\
\hline Temperature & $130^{\circ} \mathrm{C}$ & $100^{\circ} \mathrm{C}$ & $100^{\circ} \mathrm{C}$ & $130^{\circ} \mathrm{C}$ & $40^{\circ} \mathrm{C}$ \\
\hline
\end{tabular}

\section{BENEFITS TO THE FUNDING DOE OFFICE'S MISSION}

Oak Ridge National Laboratory is the home to HFIR, which provides the highest flux reactor-based source of neutrons for research in the United States. Through the neutrons generated and world-class collection of instrumentation and infrastructure, HFIR provides the platform to advance fundamental and applied research in chemistry, physics, material science, and isotope production for medical, industrial, and research purposes. This platform has provided opportunities for users, both public research institutions and private companies, to build partnerships with ORNL researchers that accelerate the development of solutions and technologies to address key needs in the US and international community.

This project specifically addressed the DOE mission to "...advance nuclear power as a resource capable of making major contributions in meeting our nation's energy supply, environmental, and energy security needs by focusing on the development of advanced nuclear technologies." The development of new sensor technologies for advanced reactors and development of condition monitoring technology to provide timely and cost-efficient management of I\&C investment in current nuclear reactors provide two ways to preserve and advance the investment in nuclear energy within the US. 


\section{TECHNICAL OUTCOMES}

\subsection{HFIR INSTRUMENTED GAMMA SYSTEM INTEGRATION}

The instrument gamma irradiation system at HFIR GIF was developed to enable experimenters to build custom instrumented experimental assemblies that can be inserted into the spent fuel assemblies. The spent fuel assemblies are located in the HFIR reactor bay pool (Fig. 1) and depending on when the fuel assembly was removed from HFIR the dose rate from gamma irradiation can range from $30 \mathrm{~Gy} / \mathrm{h}$ to $1000 \mathrm{kGy} / \mathrm{hr}$. Because of the nature of the decay and geometry associated with the fuel assembly, dose rate changes (Fig. 2) with time and position within the fuel element. These factors must be accounted for when planning irradiations for exposures longer than a couple of weeks and when high dose rates are needed with spent fuel assemblies that have recently been removed from the HFIR reactor.

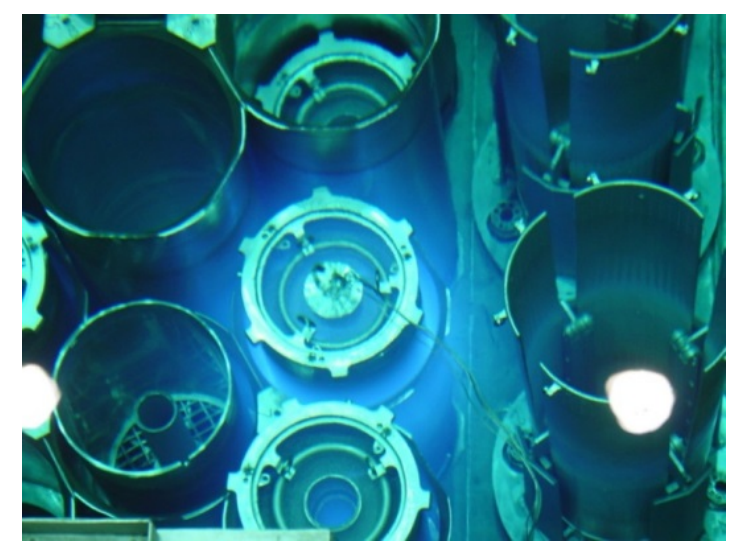

Fig. 1. Overhead view of spent fuel at the HFIR Gamma Irradiation Facility.

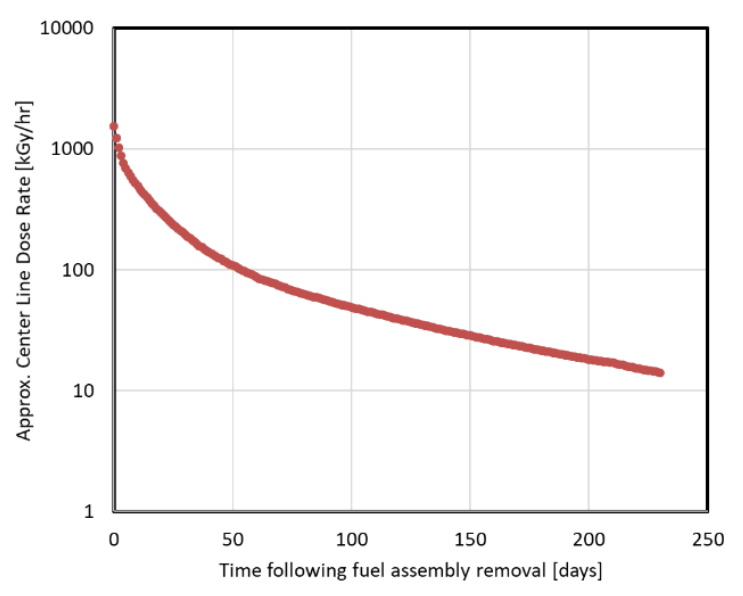

Fig. 2. Representative decay in dose rate at center of fuel element.

The initial instrumented gamma system configuration was utilized previously for the exposure of nanodielectrics, harvested NPP insulation and jackets, and prototype mineral insulated cables. In each of these configurations, experimental assemblies were lowered into a gamma irradiation canister with a nominal inner diameter of 3.5" and length of 24" (Fig. 3) and the instrumented connections were fed through a lower extension tube (Fig. 4) that was sealed to the top of the gamma irradiation canister. The top of the lower extension tube had a slight angle at the top to route the leads and connectors out of direct line of sight on the canister to avoid reflective radiation that could prematurely age connectors. The connectors were mated to the upper extension tube (Fig. 5) which was connected to the umbilical line, approximately 75' long, that leads from the reactor bay to the experimental area of HFIR. The umbilical served as the interface to the exchange gas that was provided from an external gas panel and for instrumented connections to a HFIR control system in the experimental area (Fig. 6). The instrumented connections consisted of seven type K thermocouple connections, four-wire heater control leads rated for $208 \mathrm{~V}$ and $3 \mathrm{~A}$, and two custom high voltage $(\approx 1 \mathrm{kV})$ BNC cables.

While the instrumented gamma system had successfully operated for several years, the experimental scope for the sensors and the cables required some modifications to the instrumented gamma system in order to accommodate the cable lengths and number of instrumented connections for this work scope. For cable irradiations in the HFIR GIF, additional space was needed to accommodate two $25^{\prime}$ cables between the irradiation canister and the upper extension tube. To achieve this with minimal modification to the assembly, additional fittings including a large stainless steel cross were added between the lower and upper 
extension tubes (Fig. 7). This cross would hold the majority of the length before it looped down into the irradiation canister. Fig. 8 shows the trial winding by AMS, which included an instrumented test of the cable impedance with the AMS CHAR Cable Condition Monitoring System to assure that the cable configuration from this trial winding did not negatively impact the quality of their measurement prior to insertion. For the electrical connections for the sensor irradiation, additional type $\mathrm{N}$ thermocouple wiring, type $\mathrm{K}$ thermocouple wiring, and $8 / \mathrm{C}$ cabling were needed to accommodate the prototype multi-element temperature sensors and pressure sensors.

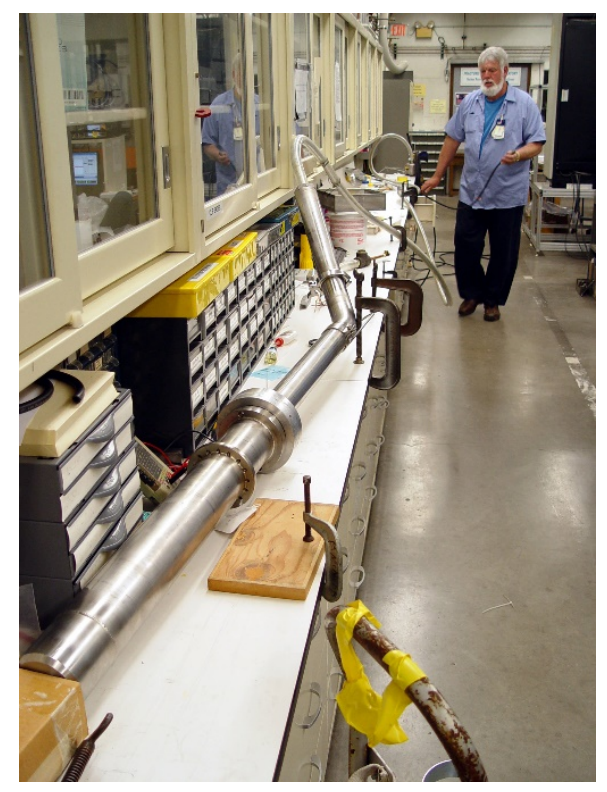

Fig. 3. Gamma irradiation canister that was utilized for exposure of experimental assemblies at the HFIR GIF with lower and upper extension tubes during leak check.

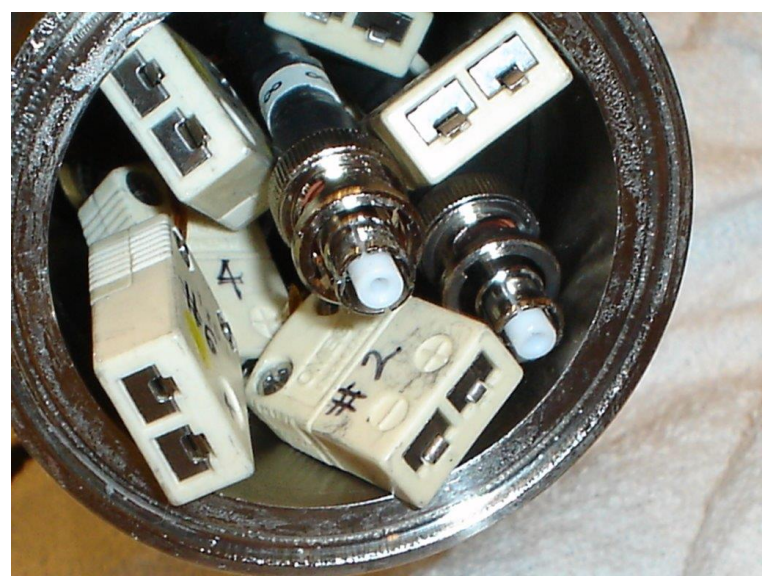

Fig. 5. Instrumentation connections at the upper extension tube that link the experiment in the gamma irradiation canister to the umbilical.

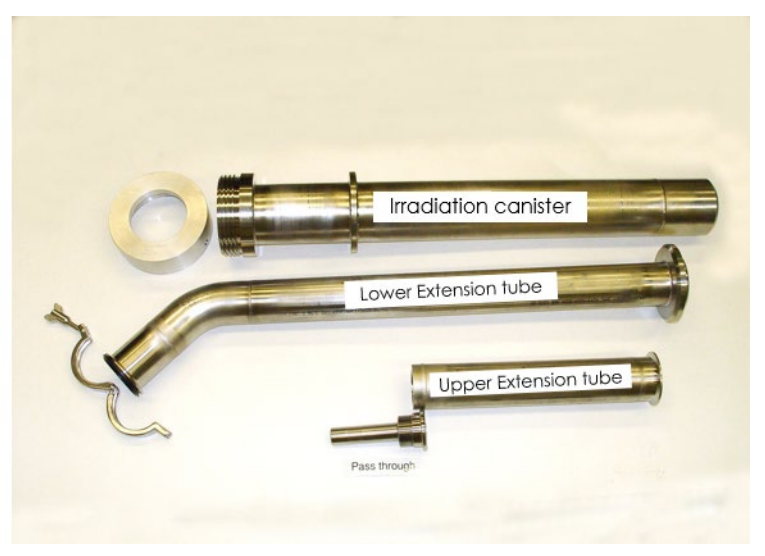

Fig. 4. Lower and upper extension tubes that served as a bridge for instrumentation connections between the gamma irradiation canister to the umbilical.

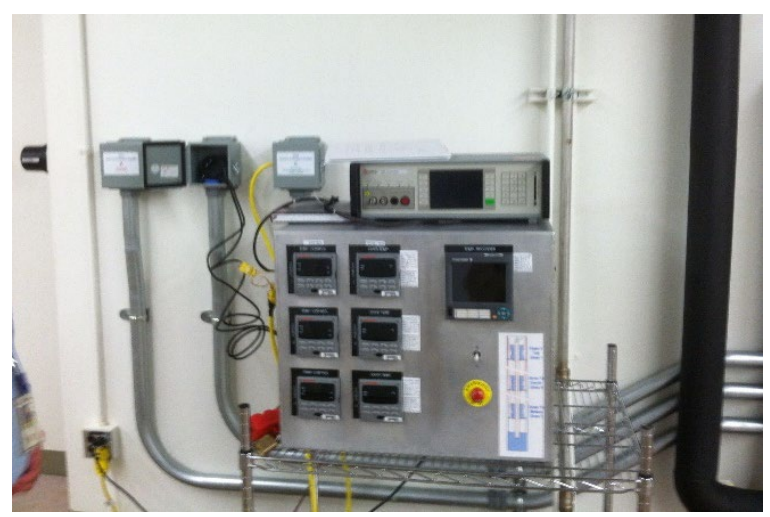

Fig. 6. HFIR instrumented control system in HFIR experimental area that interfaces with the experimental assemblies while in the HFIR GIF. 


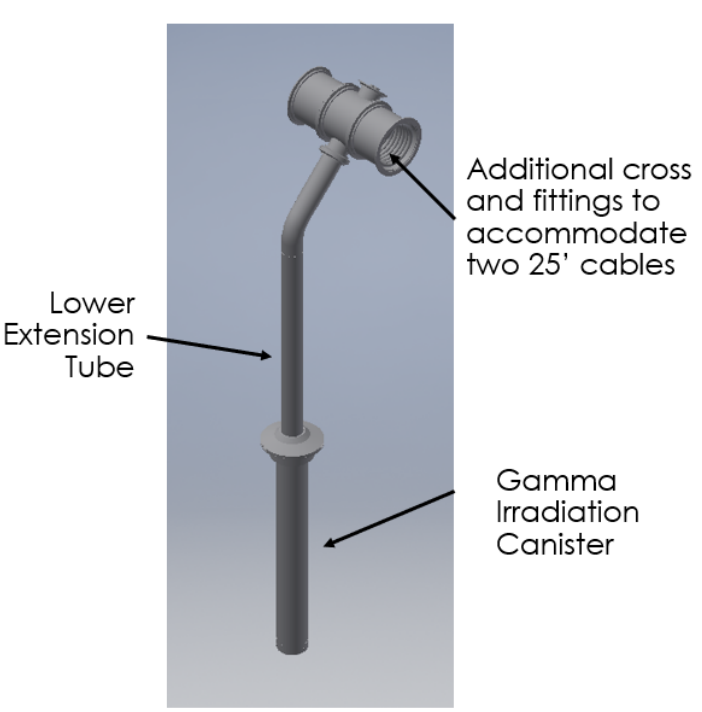

Fig. 7. Modification of physical connections in the instrumented gamma system for cable irradiations in the HFIR GIF with additional fittings between the lower and upper extension tubes.

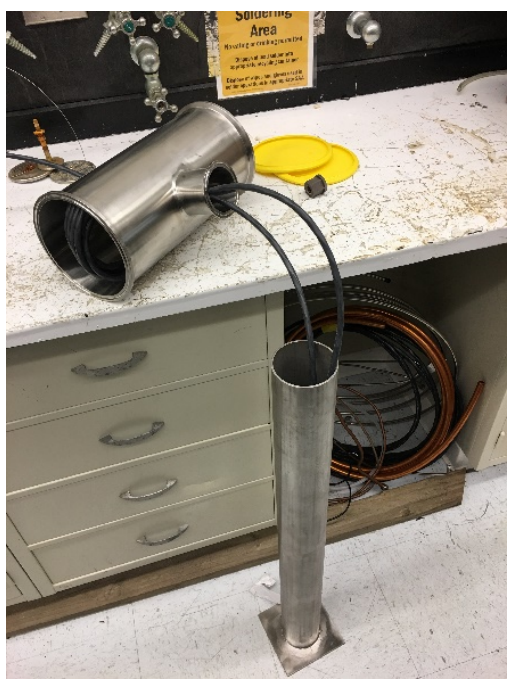

Fig. 8. Trial cable winding in large cross fitting to accommodate 25-foot-long cables between irradiation canister and the upper extension tube.

\subsection{EXPERIMENTAL ASSEMBLY DESIGN AND FABRICATIONS}

\subsubsection{Sensor Irradiation Assembly}

In order to functionally test the prototype temperature and pressure sensors, an experimental assembly was designed and fabricated to support their irradiation in the HFIR GIF (Fig. 9). Two prototype temperature sensors and two prototype pressure sensors were attached to a small cylinder with a volume of $0.189 \mathrm{~L}$ that could be pressurized to $50 \mathrm{psig}$ ( $3.5 \mathrm{barg}$ ) with nitrogen gas through a check valve prior to the experimental assembly being carried into the HFIR reactor bay for insertion into the gamma irradiation canister. The check valve was attached to a long $1 / 4$ " OD tube that mated to a $1 / 4$ " tee between the cylinder and one of the sensors under test. The length of the tube was chosen so that, like the sensor connections at the umbilical at the top of the lower extension tube, the check valve would be out of line of sight to minimize exposure during irradiation. The volume of the cylinder was chosen so that if expected pressurization from heating of the cylinder occurred, the release of gas into the irradiation canister, which had a nominal volume of 2.7 L, would stay below the 15 psig limit in the irradiation canister.

To examine the functional behavior of the prototype temperature and pressure sensors during their irradiation, two $150 \mathrm{~W}$ heaters were attached to the cylinder. With a fixed volume in the cylinder, the heaters would increase the temperature and pressure of the cylinder and provide the means to measure the transient response of the sensors during the irradiation. The goal was to elevate the cylinder temperature from the pool temperature at approximately $40^{\circ} \mathrm{C}$ to $130^{\circ} \mathrm{C}$ and increase the pressure by approximately $25 \%$. The response of the sensors would be tracked by AMS with their data acquisition system while control thermocouples on the cylinder were utilized by the HFIR control system (Fig. 6) to maintain the cylinder temperatures between $40^{\circ} \mathrm{C}$ to $130^{\circ} \mathrm{C}$. 

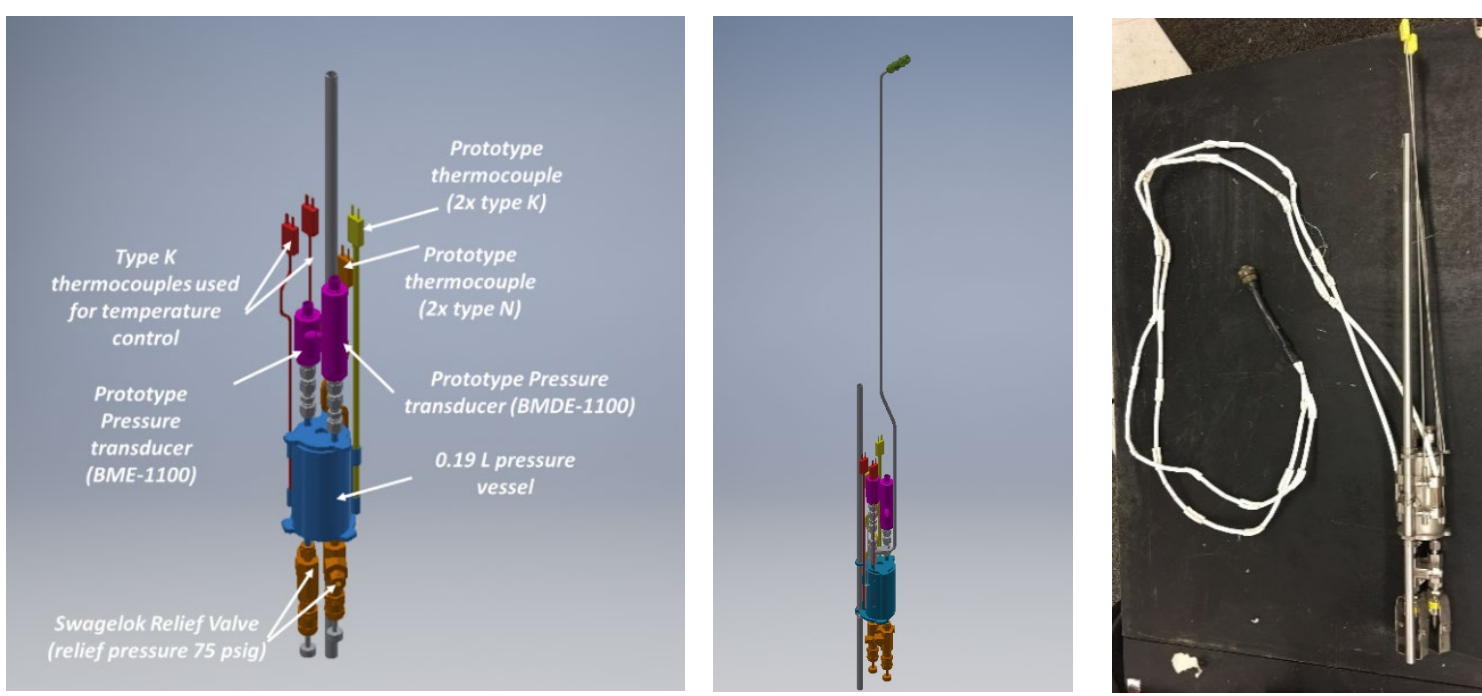

Fig. 9. Schematic diagram of sensor irradiation assembly design (left), sensor irradiation assembly with $1 / 4$ " stainless steel tube and $1 / 3$ psig check valve at top (center), \& actual sensor irradiation assembly (right).

The prototype temperature sensors to be irradiated are a concept under development by AMS to address higher temperatures and irradiation exposures that are expected in advanced reactors. AMS holds a patent for a multi-element temperature sensor that incorporates two thermocouples and one RTD sensing element within the same probe and is referred to as the Triple Temperature Sensor (TTS). It was designed to provide diversity and redundancy of measurements and facilitate enhanced sensor diagnostics such as in-situ response time testability and in-situ calibration testability. Five prototype TTS probes were manufactured by the Delta-M Corporation of Oak Ridge, TN for AMS under a DOE SBIR for testing and evaluation. Three of the TTS probes were built with Type-K thermocouples (TTS-K), and two of the TTS probes were built with Type-N thermocouples (TTS-N). One of each type of TTS probe were included in the irradiation test program at HFIR. A picture of the two sensors is shown in Fig. 10.

Prior to the irradiation, the TTS sensors were thermally aged for approximately 2 weeks at $420^{\circ} \mathrm{C}$. The calibration of the various temperature elements was checked before and after the exposure to high temperatures. Operation at the elevated temperatures had no effect on the accuracy of the sensor temperature measurements.

The candidate pressure sensors included in the irradiation test program were manufactured by Kulite Semiconductor Products, Inc. and were provided to AMS for evaluation. Kulite supplies sensors for aerospace, automotive, industrial, marine, and military applications and is interested in the next-generation nuclear reactor market. Kulite pressure transducers are dielectrically isolated, silicon-on-insulator (SOI) devices. Multiple silicon layers are arranged as: 1) a N-type silicon layer micromachined as a mechanical pressure sensitive diaphragm, 2) a silicon dioxide dielectric isolation layer, and 3) a layer of P-type silicon consisting of four strain gauges patterned into a Wheatstone bridge circuit.[1] A picture of a Kulite pressure and differential pressure sensor is shown in Fig. 11. The compact form factor of the Kulite sensors is apparent as shown in the picture.

The Kulite pressure sensors (rated for high-temperature operation) were also subjected to 2 weeks of exposure to high temperature at $140^{\circ} \mathrm{C}$. The pressure sensor was not affected by the thermal aging; however, the differential pressure sensor exhibited drift in output signal over the period of operation at elevated temperature.

[1] A. Kurtz, A. Ned, S. Goodman, A Epstein, "Latest Ruggedized High Temperature Piezoresistive Transducers," NASA 2003 Propulsion Measurement Sensor Development Workshop, Huntsville, Al, (2003). 


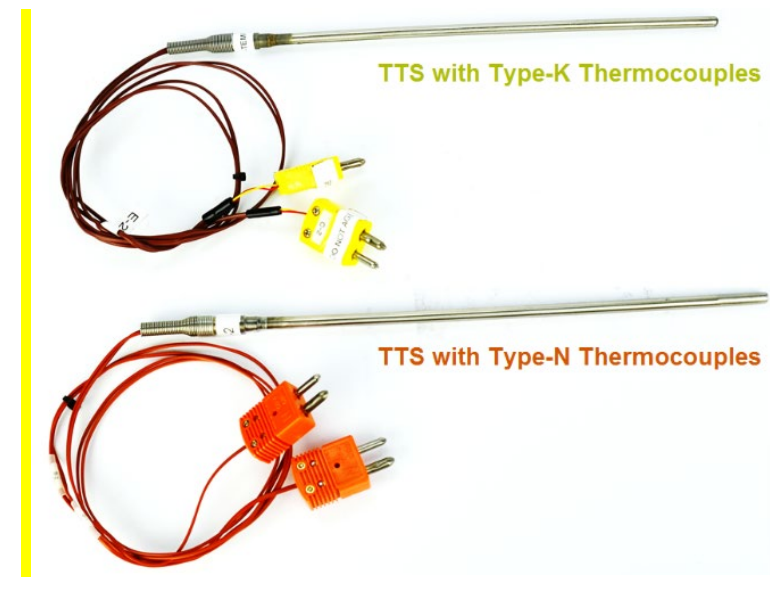

Fig. 10. Prototype type $K$ and type $N$ dual thermocouple/RTD assemblies that were examined during sensor irradiation at the HFIR GIF.

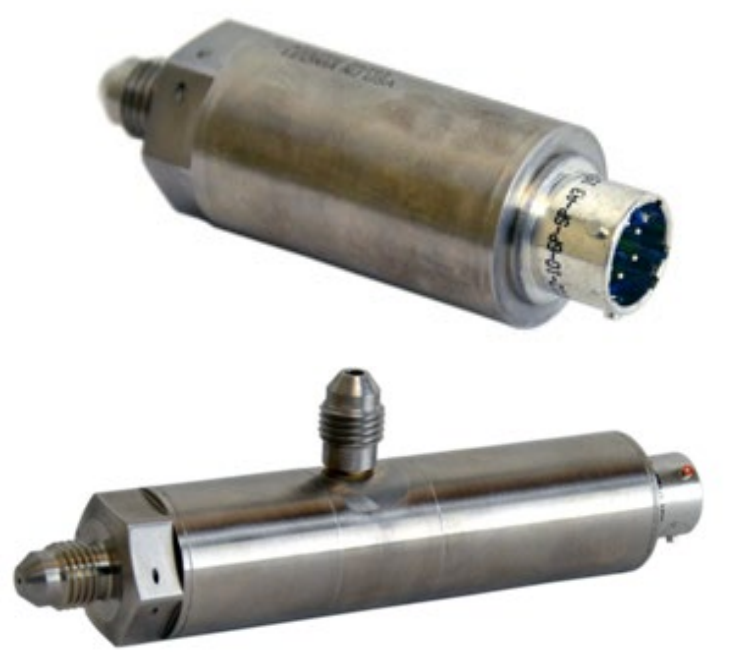

Fig. 11. Absolute and differential pressure sensors that were examined during sensor irradiation at the HFIR GIF.

\subsubsection{Cable Irradiation Assembly}

For the cable irradiation, an experimental assembly (Fig. 12) was designed to accommodate the heating of the cable and the companion NPP insulation and jacket samples. Within the irradiation canister, two aluminum blocks would be secured to a central multizone heater in order to heat the two I\&C cables and their companion insulation and jacket samples to the specified temperatures in Table 1 . High voltage $(\approx 1$ $\mathrm{kV}$ ) BNC terminations would be placed on both ends of the I\&C cables and their connection made to the $\mathrm{BNC}$ cables that are part of the instrumented gamma system umbilical instrumentation and control line.

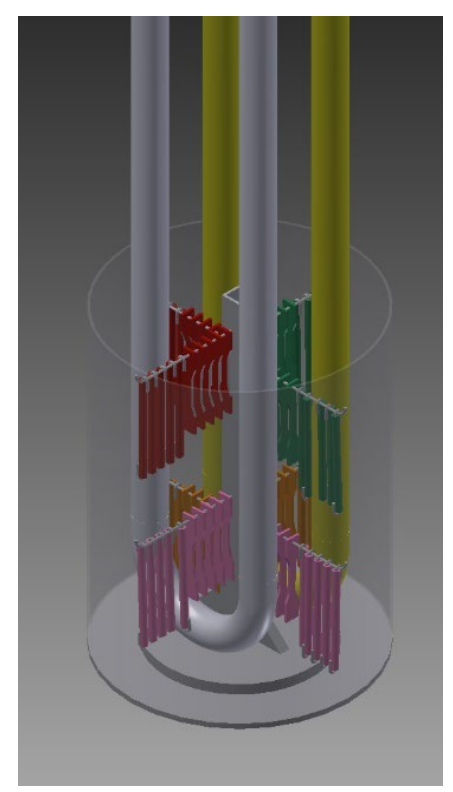

Fig. 12. Schematic diagram of experimental assembly for cable irradiation at the HFIR GIF. 
Like the sensor irradiation, AMS would monitor the cable degradation during the irradiation with their data acquisition system while the HFIR control system would monitor and regulate the temperature in the irradiation canister at the desired conditions. Periodically after safely shutting down and locking out the HFIR control system, the irradiation canister would be removed from the HFIR GIF, the experimental assembly removed, and a fraction of the companion samples removed for analysis. This analysis would provide the context for any cable degradation that is measured by the AMS data acquisition system.

\subsection{TECHNICAL CHALLENGES \& MODIFIED SCOPE}

Unfortunately, while good technical progress was made toward completing the sensor and cable experimental assemblies, two delays impacted the schedule and required modification of the desired measurements. The first delay was related to the addition of the hardware between the lower and upper extension tubes to accommodate the two 25 - $\mathrm{ft}$ long cables within the instrumented gamma system. During a review of the hardware, it was found that the o-ring seals and their flanges needed to be modified to accommodate the increased volume and mechanical load. Given this modification and the need for a modified umbilical cord, a new instrumented gamma irradiation system was designed and fabricated to accommodate this. This fabrication unfortunately had delays related to the flanges that pushed their completion past the time frame expected for the irradiation campaign. A no-cost one year extension was applied for and granted by DOE to accommodate this delay. The second delay was from resources at HFIR that were diverted to a higher priority project in support of the HFIR mission. In the fall of 2018, abnormal performance of a fuel element during the startup of a HFIR fuel cycle occurred. HFIR operators safely removed the fuel element and it was found that fuel element manufacturing issues contributed to this issue. Technical and quality assurance resources that normally would have supported the HFIR GIF operations were prioritized to address these issues so that mission critical operations and experiments, both those postponed and in the near future, could be carried out with minimal delay.

Given these two delays and the resources expended to accommodate them, it was decided that the focus on this project would be to utilize the existing instrumented gamma irradiation system for the sensor irradiation assembly alone and come back to the cable irradiation at a later time and project when the new instrumented gamma system was completed. It should be noted that the dose rate for the experiment was below the expected $10 \mathrm{kGy} / \mathrm{hr}$ due to the age of the spent fuel element available in the HFIR GIF; however, the total accumulated dose of $3000 \mathrm{kGy}$ was unchanged. Also, operating restrictions and technical issues prohibited the operation of the test cannister at $130^{\circ} \mathrm{C}$. As such, any effects on sensor performance would solely be due to the accumulated irradiation exposure. Table 2 summarizes the environmental conditions for the modified sensor irradiation sequence.

Table 2. Summary of revised conditions for irradiation of prototype sensors at HFIR GIF.

\begin{tabular}{|c|c|c||}
\hline \multirow{2}{*}{ Test Conditions } & \multicolumn{2}{|c|}{ Sensor Tests } \\
\cline { 2 - 3 } & Test 1 & Test 2 \\
\hline Avg. Dose Rate & $5.9 \mathrm{kGy} / \mathrm{hr}$ & $5.9 \mathrm{kGy} / \mathrm{hr}$ \\
\hline Exposure Time & 10.5 days & 10.5 days \\
\hline Total Dose & $1500 \mathrm{kGy}$ & $1500 \mathrm{kGy}$ \\
\hline Temperature & $\sim 45^{\circ} \mathrm{C}$ & $\sim 45^{\circ} \mathrm{C}$ \\
\hline
\end{tabular}


With the use of the existing instrument gamma irradiation system, only one of the two pressure sensors could be measured during the irradiation with the sensor connections available. The test plan was adapted to monitor one of the two pressure sensors continuously throughout the irradiation, and only check the second sensor during the period between test 1 and test 2 and again at the conclusion of the tests.

Another challenge encountered was the intermediate connection between the GIF's existing type K thermocouple wiring and the type $\mathrm{N}$ wiring of the prototype TTS-N sensor assembly. The transition between Type $\mathrm{N}$ and Type $\mathrm{K}$ wiring at the GIF instrumentation interface created a secondary thermocouple junction that caused variations in the TTS-N thermocouple output in response to any changes in temperature above the HFIR reactor pool. There was no effect on either RTD signal or the Type K thermocouple signals. A cross-calibration correction based on the two RTD signals averaged with the two Type K thermocouple signals was used to offset the Type $\mathrm{N}$ thermocouple signals to compensate for the effect of the secondary junction.

\subsection{SENSOR IRRADIATION PERFORMANCE EVALUATION}

\subsubsection{Sensor Irradiation Assembly \& Insertion Test 1}

After completion of the reviews required for the insertion of the sensor irradiation assembly into the GIF, sensor irradiations began in August 2019. An initial dosimetry run was performed at the spent fuel assembly with the highest available dose rate to verify the dose rate at the test assembly and estimate the length of time needed to obtain the desired total dose. Working with the staff in the HFIR reactor bay and the experiment area, the sensor irradiation assembly was inserted into the gamma irradiation canister, fed through the lower extension tube and connected to the umbilical to verify electrical connections (Figs. 13, $14 \& 15)$, and lowered into the fuel element (Fig. 16). Just prior to insertion into the fuel element, it was found that no signal could be obtained from the pressure sensor. Rather than incur additional delays, the decision was made to proceed with the experiment without monitoring the pressure signal.

AMS subsequently performed additional troubleshooting of the problem which identified that HFIR's coax cables were cut short of the test assembly and were not useable for the pressure sensor test. After further evaluation, it was determined to disconnect the assembly heaters at the end of the first test period and use the heater wiring for the pressure sensor power and signal connections.

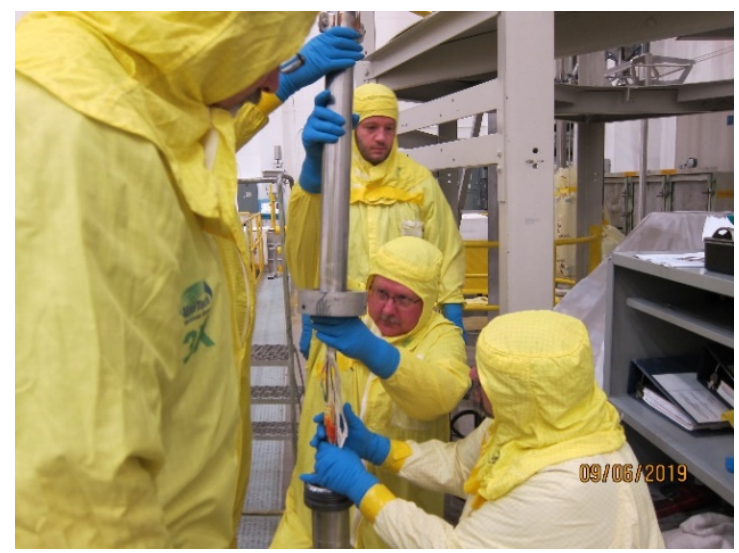

Fig. 13. Insertion of the sensor experimental assembly into the gamma irradiation canister for the instrumented gamma system in the HFIR reactor bay.

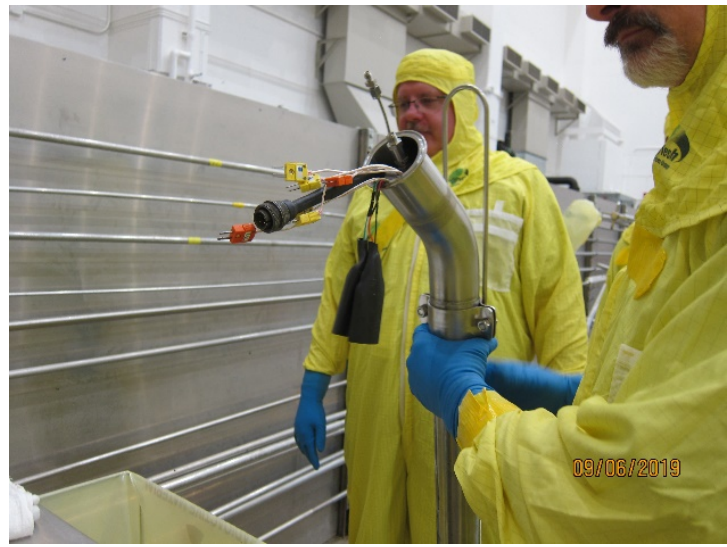

Fig. 14. Feedthrough of sensor cabling through lower extension tube for the instrumented gamma system in the HFIR reactor bay. 


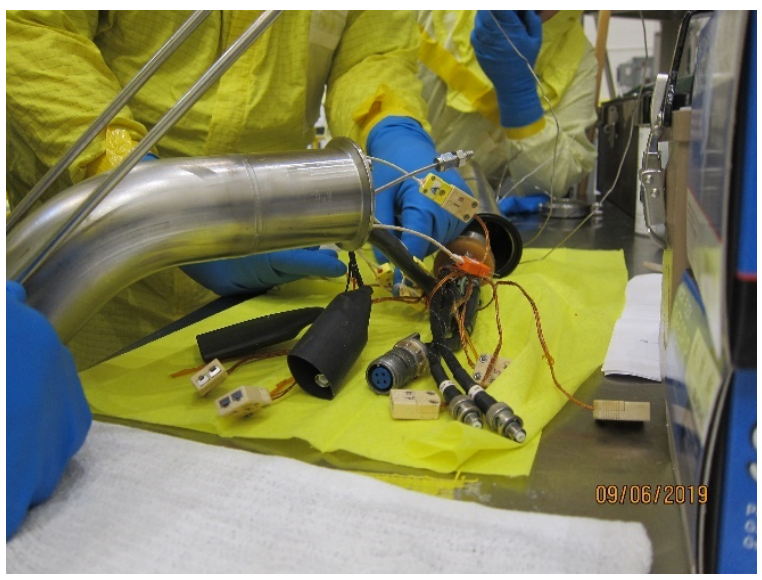

Fig. 15. Verification of instrumentation connections for sensor irradiation assembly for the instrumented gamma system in the HFIR reactor bay.

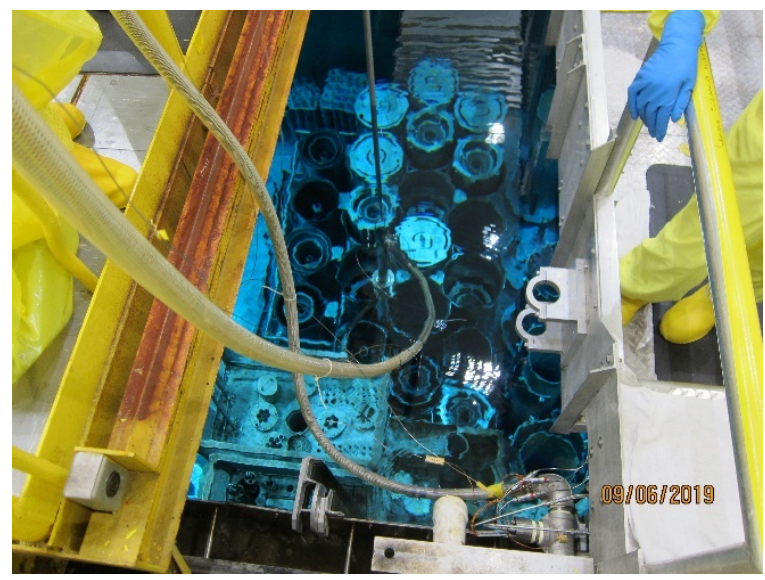

Fig. 16. Insertion of instrumented gamma system into spent fuel element in HFIR GIF located in HFIR reactor bay.

The first irradiation sequence for the sensor test assembly was cut short at seven days when an issue with the gas pressure regulator supplying the compressed air to the instrumented gamma system required removal of the experiment from the HFIR GIF. This resulted in an accumulated dose of $990 \mathrm{kGy}$. The TTS$\mathrm{K}$ and TTS-N temperature measurements tracked the actual assembly temperature reasonably well during the first test period; however, detailed review of the data identified an issue with the thermocouple reference junction measurements. As such, the AMS software used to monitor the sensor output signals was revised between Test 1 and Test 2 .

\subsubsection{Sensor Performance Irradiation \& Insertion Test 2}

When the first test period was cut short at seven days and $1000 \mathrm{kGy}(100 \mathrm{MRad})$ due to failure of the air pressure regulator, the test delay was used to proceed with removal of the cylinder heaters and connection of the heater wiring to the pressure sensor power supply and signal output. Each of the two pressure sensors were then tested one at a time to check their operation after exposure to $1000 \mathrm{kGy}$. One of the pressure sensors was found to operate normally; however, the second sensor failed the operability test.

The operable pressure sensor was then re-connected and configured for monitoring for the remainder of the test. The output of the pressure sensor was recorded after insertion of the test assembly into the reactor pool and plotted versus temperature as shown in Fig. 17. The initial sensor output measurement of 44.8 PSIA at $75^{\circ} \mathrm{F}$ and the nominal increase in pressure to $46.8 \mathrm{PSIA}$ at $100^{\circ} \mathrm{F}$ is consistent with normal sensor operation. However, after the test assembly temperature settled initially at about $103^{\circ} \mathrm{F}$, the pressure sensor output continued to increase independent of any change in temperature.

The sensor output is initially normal at $1000 \mathrm{kGy}\left(100 \mathrm{MRad}\right.$ at $\left.100^{\circ} \mathrm{F}\right)$, However, the output signal then increases steadily from about 47 PSIA to 73 PSIA as the radiation dose increases from 1000 to $3000 \mathrm{kGy}$ (100 to $300 \mathrm{MRad})$. Several different evaluations were performed to confirm that the ongoing change in pressure sensor output was not caused by any actual change in pressure, change in assembly temperature, or any other issue with the sensor test configuration. As such, the change in output is attributed to the irradiation. The pressure sensor output is plotted versus accumulated radiation dose as shown in Fig. 18. 


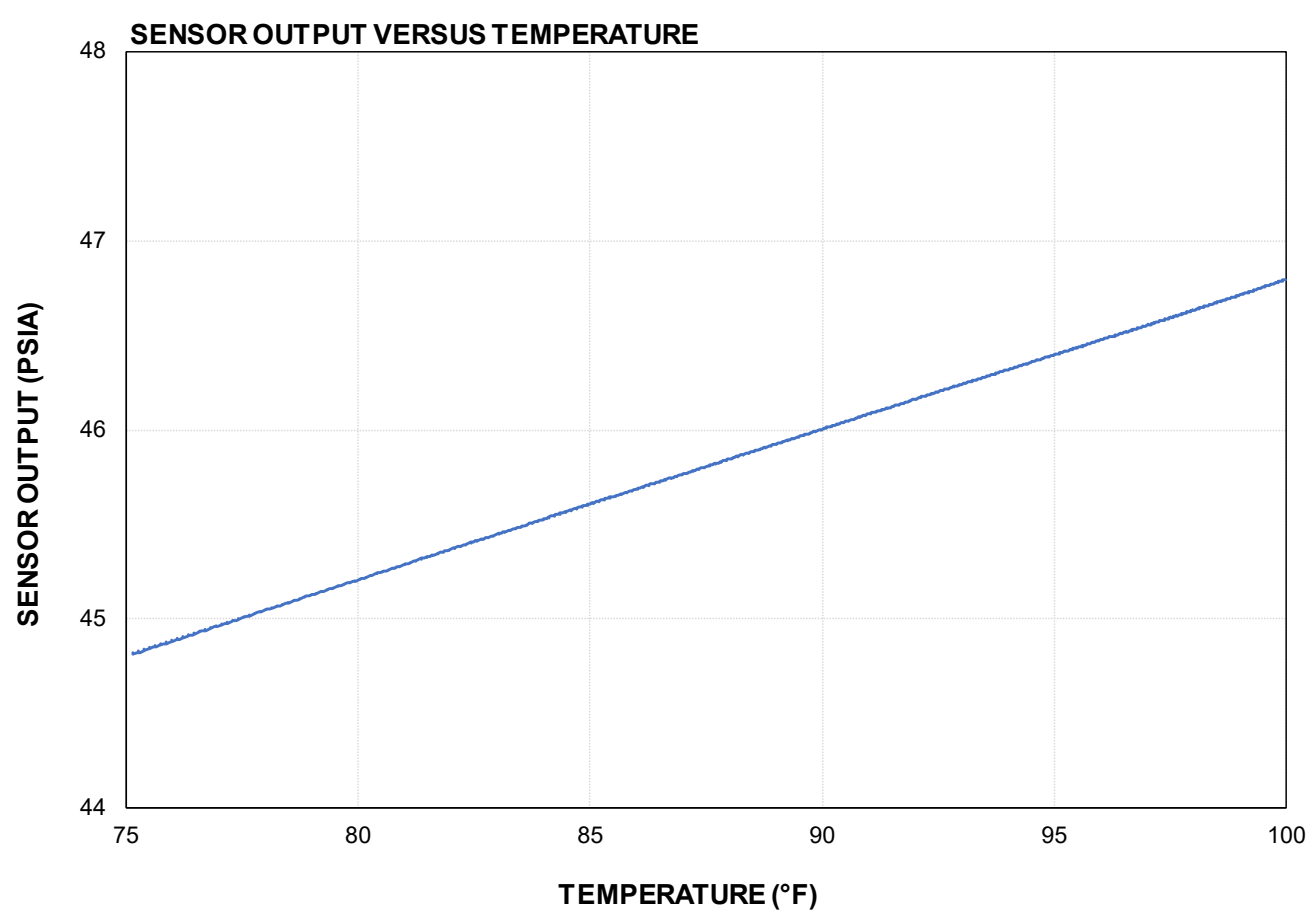

Fig. 17. Pressure Signal Versus Temperature $\left(7^{\circ} \mathrm{F}\right.$ to $\left.100^{\circ} \mathrm{F}\right)$

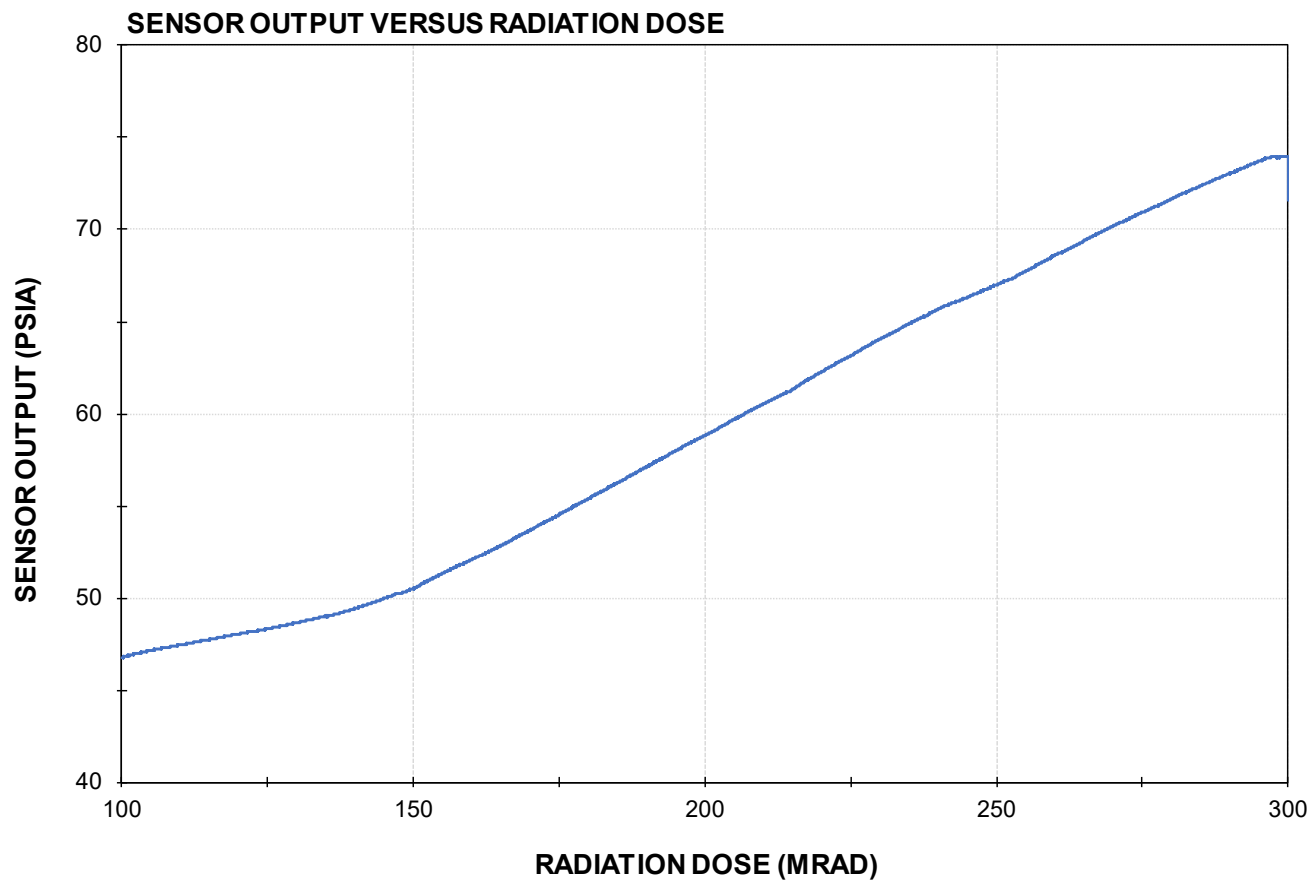

Fig. 18. Pressure Signal Versus Radiation Dose (1000 kGy to 3000 kGy) 
The temperature of the test assembly was measured by the two AMS TTS sensors for the duration of the experiment which consisted of the seven days for Test 1 followed by the sixteen days for Test 2. Each TTS sensor consists of a four wire resistance temperature detector (RTD) and two thermocouple elements which are built into the leadwires of the RTD. The measurements from the two AMS TTS sensors (two RTD elements and four thermocouple elements) tracked the pool temperature consistently for the duration of Test 2 over the span of approximately 380 hours. The temperature measurement data from the six sensing elements are plotted in Fig. 20. There were some fluctuations in the Type $\mathrm{N}$ thermocouple signals during the first 100 hours of Test 2 due to variation in temperature above the reactor pool around the secondary junction created by the connection of the Type $\mathrm{N}$ thermocouple wires to the GIF Type $\mathrm{K}$ wires.

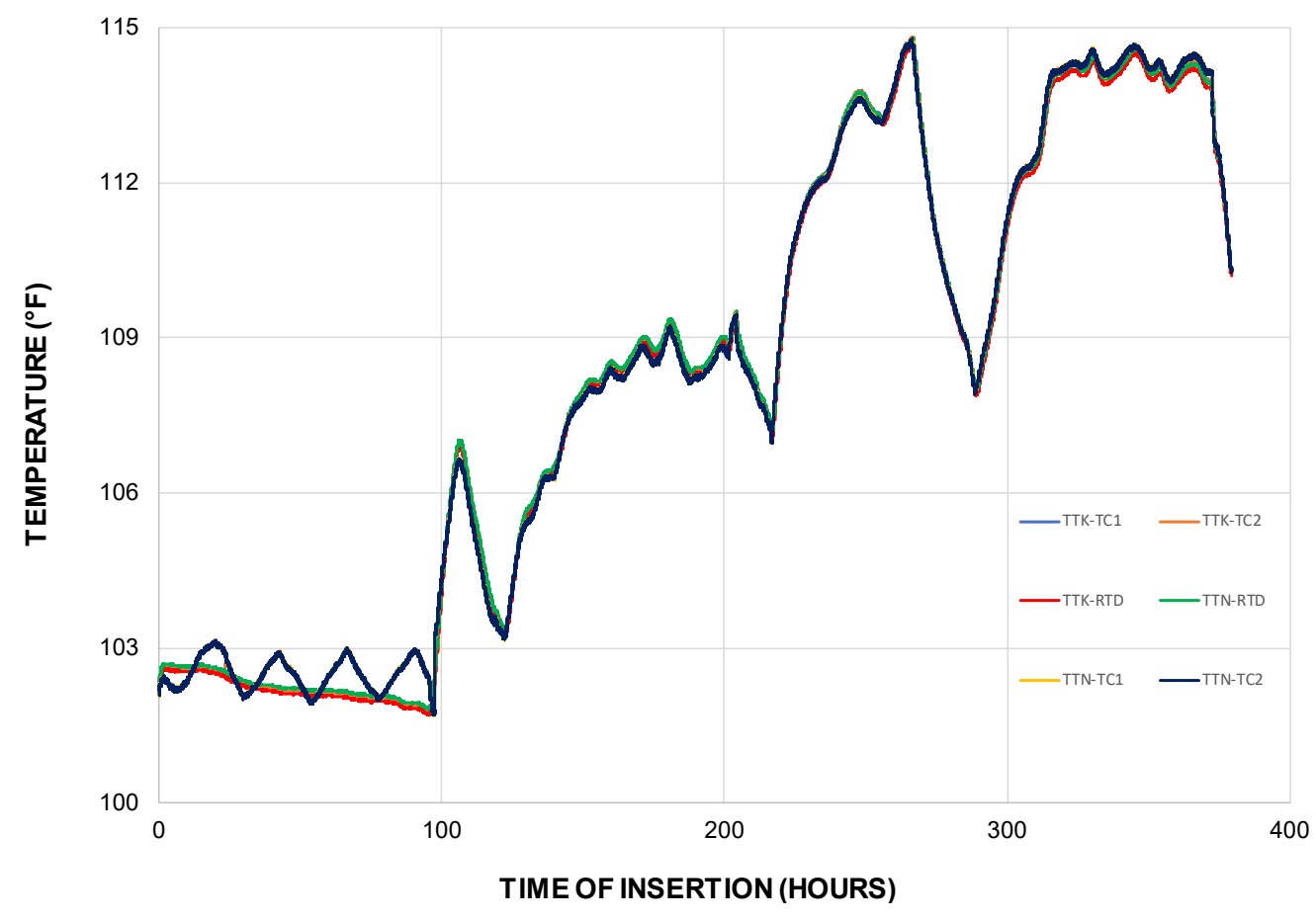

Fig. 20. Temperature Measurements During Test 2 (1000 kGy to 3000 kGy)

\subsubsection{Post-test Evaluation}

At the conclusion of the irradiation, all the pressure and temperature sensors were removed from the test assembly, verified to have no radioactive contamination, and were released to AMS for post-test evaluation. As shown in Table 3, Pressure Sensor \#1 is an absolute pressure sensor that measures pressure input of 0 to 100 PSIA with a corresponding linear signal output of 0 to $100 \mathrm{mV}$. Before irradiation, the pressure sensor output followed the sensor input normally. After irradiation, the sensor output ranged between 63 to $100 \mathrm{mV}$ versus 0 to $100 \mathrm{mV}$ and was generally non-functional at an input pressure of 60 PSIA and below.

As shown in Table 4, Pressure Sensor \#2 is a differential pressure sensor that measures pressure difference of 0 to $3.5 \mathrm{Bar}$ ( $\sim 51$ PSID). The sensor output followed the pressure input as expected prior to irradiation, but after irradiation, sensor output ranged only about $10 \mathrm{mV}$ versus $100 \mathrm{mV}$. Both sensors have been returned to the manufacturer for additional evaluation to determine the cause of failure.

Table 3. Pressure Sensor \#1 Post-Test Evaluation 


\begin{tabular}{|c|c|c|c|}
\hline \hline \multirow{2}{*}{ Input (PSIA) } & \multicolumn{3}{|c|}{ Output Signal (mV) } \\
\cline { 2 - 4 } & Expected & Pre-rad & Post-rad \\
\hline 20 & 20.0 & 19.7 & 63.2 \\
\hline 40 & 40.0 & 39.5 & 65.6 \\
\hline 60 & 60.0 & 59.3 & 68.8 \\
\hline 80 & 80.0 & 79.4 & 79.9 \\
\hline 100 & 100.0 & 99.1 & 94.7 \\
\hline
\end{tabular}

Table 4. Pressure Sensor \#2 Post-Test Evaluation

\begin{tabular}{|c|c|c|c|}
\hline \multirow{2}{*}{ Input (BarD) } & \multicolumn{3}{|c|}{ Output Signal (mV) } \\
\cline { 2 - 4 } & Expected & Pre-rad & Post-rad \\
\hline 0.0 & 0 & 0.1 & -8.5 \\
\hline 0.7 & 20.0 & 20.3 & -6.8 \\
\hline 1.4 & 40.0 & 40.4 & -5.0 \\
\hline 2.1 & 60.0 & 60.5 & -2.9 \\
\hline 2.8 & 80.0 & 80.7 & -0.2 \\
\hline 3.5 & 100.0 & 100.7 & 3.5 \\
\hline
\end{tabular}

The TTS sensors outputs were measured at $0^{\circ} \mathrm{C}, 100^{\circ} \mathrm{C}$, and $300^{\circ}$ using calibrated test equipment traceable to national standards. The results of the calibration check were compared to baseline information obtained before the irradiation. The differences in measurements (drift) are presented in Table 5. There was no appreciable drift in signal output for either of the two RTD elements. However, there was $\sim 0.3^{\circ} \mathrm{C}$ drift in the ice point measurement for the Type $\mathrm{N}$ thermocouple elements and $\sim 0.4^{\circ} \mathrm{C}$ drift for the Type $\mathrm{K}$ thermocouple measurements at $300^{\circ} \mathrm{C}$. These variations in thermocouple measurements are relatively insignificant compared to the general accuracy and repeatability of standard industrial thermocouples.

Table 5. Temperature Sensor Drift

\begin{tabular}{|c|c|c|c|c||}
\hline \multirow{2}{*}{$\begin{array}{c}\text { Item } \\
\#\end{array}$} & \multirow{2}{*}{ Tag Name } & \multicolumn{3}{|c|}{ Test Temperature $\left({ }^{\circ} \mathbf{C}\right)$} \\
\cline { 3 - 5 } & & $\mathbf{0}$ & $\mathbf{1 0 0}$ & $\mathbf{3 0 0}$ \\
\hline 1 & TTK-RTD & 0.01 & 0.03 & 0.08 \\
\hline 2 & TTN-RTD & 0.00 & 0.00 & 0.00 \\
\hline 3 & TTK-TC1 & -0.03 & 0.10 & 0.34 \\
\hline 4 & TTK-TC2 & -0.03 & 0.12 & 0.40 \\
\hline 5 & TTN-TC1 & -0.22 & 0.06 & 0.09 \\
\hline 6 & TTN-TC2 & -0.38 & 0.14 & 0.14 \\
\hline
\end{tabular}

\section{SUBJECT INVENTIONS (AS DEFINED IN THE CRADA)}

None. 


\section{COMMERCIALIZATION POSSIBILITIES}

This work remains at a preliminary stage. The irradiation to $3000 \mathrm{kGy}$ has established a baseline of reliability of the performance for the prototype thermocouple assemblies and pressure sensors, but additional work is required to provide the necessary information for an end-user or possibly a regulator to consider these sensors for usage in safety related applications. For the temperature sensors, further testing at higher accumulated radiation dose and temperatures are needed to define the failure points, establish the functional boundaries, and address any potential sensor material modifications that are required. For the pressure sensors, additional evaluation of the sensor failure mechanism needs to be performed and sensor design modified as needed to accommodate a high radiation operating environment.

\section{PLANS FOR FUTURE COLLABORATION}

On-going collaborations are planned between AMS and ORNL in the area of cable R\&D in support of advanced reactor development. This collaboration would be similar to this project to assess the feasibility of current insulations and conductor in I\&C cables to determine the consequence of the environmental operating boundaries such as temperature, pressure, radiation, and accident scenarios that are decidedly different than current IEEE 323 and 383 standards for current nuclear power plants.

As it relates to follow-on work related to sensor $R \& D$, these results have been shared with industrial partners interested in their implications to their advanced reactor concepts. ORNL has prepared an updated cost and schedule estimate given the technical challenges faced through this project and is actively working to secure funds, either internal or external, resolve them to improve the capability of the HFIR GIF relative to this topical area.

\section{CONCLUSIONS}

The irradiation of prototype temperature and pressure sensors was successfully completed at the HFIR GIF. This work has shown that the prototype temperature sensors are radiation resilient up to $300 \mathrm{MRad}$ (3000 $\mathrm{kGy}$ ). Additional testing and performance verification at higher operating temperatures (up to $300^{\circ} \mathrm{C}$ ) and radiation dose up to $1 \mathrm{Grad}(10000 \mathrm{kGy})$ would be the next step for sensor development. The candidate pressure sensors failed between 100 to $300 \mathrm{MRad}$; however, they appear to have remained functional through $100 \mathrm{MRad}$. These sensors do not appear to be currently suitable for long-term operation in an irradiation field with accumulated dose over $100 \mathrm{MRad}$. Additional evaluation is needed to determine if the sensors can be modified for improved tolerance to high radiation or if an alternate design needs to be considered.

Design for the irradiation of I\&C cables and companion I\&C jacket and insulation samples was completed but programmatic delays related to upgrading the existing instrumented gamma system at the HFIR GIF and higher priority tasks with HFIR operations prevented this work from being completed. Despite these issues, areas of future collaborations in I\&C cables and sensors were identified between ORNL and AMS as well as other industry partners and discussions toward these projects is on-going.

\section{ACKNOWLEDGEMENTS}

The activities in this report were enabled by the support provided by Chris Bryan, Michael Crowell, Jorge Navarro, Krystin Stiefel, and the Nuclear Safety \& Experiment Analysis Group at HFIR for providing the 
needed support to assemble and shepherd the necessary paperwork through the USQD process. The authors would also like to thank the support of the HFIR Shift Supervisor and Reactor Controllers during the insertion and removal of the instrumented gamma from the HFIR GIF. 